\title{
Currículo e gênero: produção e naturalização das diferenças na escola
}

\author{
Julia Mayra Duarte Alves* \\ Laura Cristina Vieira Pizzi**
}

\begin{abstract}
Resumo
Este artigo apresenta uma pesquisa no qual se analisou a produção de subjetividades em uma escola de ensino fundamental em um bairro de Maceió/AL. A pesquisa problematizou a demarcação de gênero constituída a partir de duas atividades econômicas e culturais presentes no lugar, a produção da renda filé e a pesca. A partir dos enunciados que circulam na escola sobre essas atividades, com base nas ferramentas teóricas fornecidas por Foucault, a pesquisa analisou os discursos produtores de subjetividades que estão operando predominantemente na escola com base nessa divisão sexual do trabalho. As estratégias metodológicas utilizadas foram observações, entrevistas e grupos de discussão com estudantes. Observamos que os modos de ser dos sujeitos são resultados de técnicas de governo das relações de gênero que objetivam determinar as possibilidades de ser e viver, estabelecendo fronteiras fortemente demarcadas entre o que é feminino e o que é masculino.
\end{abstract}

Palavras-chave: Currículo; Gênero; Subjetividade; Ensino fundamental.

\section{Curriculum and gender: production and naturalization of differences in school}

\begin{abstract}
\section{Considerações iniciais}

Este artigo apresenta resultados de uma pesquisa de mestrado que buscou entender como determinadas subjetividades são produzidas a partir dos enunciados que circulam no currículo de uma escola localizada em um bairro periférico e turístico de Maceió. A pesquisa problematizou a demarcação de gênero constituída com base em duas atividades econômicas e culturais presentes nesse bairro que instituem a pesca como uma atividade masculina e a produção da renda do filé ${ }^{1}$ como feminina.
\end{abstract}

This article presents a research intended to analyze the production of subjectivities in an elementary school in a neighburhood area of Maceió/AL. It also aimed at a discussion about the demarcation of gender formed by two economic and cultural activities taking place there, the production of lace of file and fishing. From the statements circulating in school about these activities, based on theoretical tools provided by Foucault, the research examined the discourses producing subjectivities in terms of gender, which goes on predominantly in school as to the sexual division of labor in the community. The methodological strategies used were observations, interviews and discussion groups with students. We noticed that the children's ways of being are the result of techniques of ruling gender relations in order to determine the possibilities of being and living, establishing borders sharply demarcated between what is feminine and what is masculine.

Keywords: Curriculum; Gender, Subjectivitie, Elementary School.

No bairro, a pesca (atividade tradicionalmente considerada masculina) foi durante muito tempo a principal fonte de renda, mas desde o final da década de 1980 vem se tornando pouco lucrativa e viável devido à degradação ambiental da lagoa que margeia a comunidade. Ao mesmo tempo, a produção e comercialização do filé (realizada, tradicionalmente, pelas chamadas rendeiras), vêm se consolidando como uma interessante possibilidade de renda em decorrência da atividade turística na região.

Essas reconfigurações econômicas locais chamaram nossa atenção e foram um convite para estudar as relações de gênero na única escola do bairro, a partir dos enunciados discursivos sobre essas atividades que, ao mesmo tempo em que demarcam, se constituem por uma forte divisão de gênero.

O filé e a pesca se apresentam, então, como elementos estratégicos para se pensar a subjetivação dos/as meninos/as que estudam na escola pesquisada e que são moradoras do bairro.

Desde o nascimento, as crianças acompanham a confecção do filé. Toda produção dessa renda acontece no ambiente doméstico. Por volta dos cinco ou seis anos de idade, as crianças começam a participar da confecção da renda, seja dentro de suas casas ou nas calçadas do bairro, à vista dos turistas e da comunidade. No cotidiano, elas começam a se interessar pela renda como atividade, observando e fazendo os primeiros pontos (MESQUITA et al, 2011).

\footnotetext{
*Endereço eletrônico: juliamdalves@gmail.com

**Endereço eletrônico: lcvpizzi@ hotmail.com
} 
A aprendizagem do filé na infância indica que essa atividade é parte crucial do processo de socialização das crianças na família e no bairro. Elas aprendem a técnica observando, em geral, as mulheres adultas (mães, tias, avós e vizinhas), que se organizam para tecer em pequenos grupos ou sozinhas em casa.

Mesquita et al (2011) apontam que, na fase incial da infância, pelo fato de o filé estar associado ao ambiente doméstico, todas as crianças aprendem e fazem a renda; no entanto, as meninas são mais incentivadas e cobradas pelo trabalho. Estas prosseguem na atividade por toda a sua vida, ou, pelo menos, por um período maior que os meninos, que, na maioria das vezes, abandonam a atividade em função da discriminação associada à feitura da renda por homens. Esse momento em que os meninos se afastam do filé coincide com a passagem pelo ensino fundamental, em especial nas séries finais, o que tornou esse período interessante para pesquisar os modos de subjetivação de gênero na escola do bairro.

A pesquisa aqui relatada buscou destacar que, além do aspecto econômico, essas atividades são centrais na produção de subjetividades das crianças que lá moram, mais especificamente, nos modos como elas vivenciam as demarcações de gênero.

\section{Currículo e subjetividade}

Nas análises sobre currículo, a pesquisa baseou-se em autores pós-estruturalistas como Silva (2006) que compreende o currículo como um campo cultural, como uma instância de produção e circulação de discursos, na qual se estabelecem lutas em torno da significação sobre os sujeitos e o mundo, impregnado de valores e práticas.

O currículo, nessa perspectiva, é entendido como um lugar de produção discursiva que forja subjetividades e que vai além do conjunto dos conteúdos escolares, sendo composto também pelas formas de organização do espaço, do tempo e pelos discursos que circulam na escola.

$\mathrm{Na}$ perspectiva pós-estruturalista, o currículo constitui regulações sociais no nível do conhecimento e da subjetividade (POPKEWITZ, 1994), ou seja, quando falamos em currículo colocamos em jogo o que deve ser conhecido, qual conhecimento é válido e autorizado a circular na escola. Ademais, o currículo não apenas informa como também guia as pessoas a pensarem de determinadas formas o seu eu no mundo, moldando/ as nossas subjetividades.
A perspectiva pós-estruturalista rejeita a hipótese de uma consciência centrada, unitária, coerente. Nesse sentido, não há um núcleo subjetivo pré-social no pensamento pósestruturalista (SILVA, 2005). Nossas subjetividades são forjadas a partir de processos sociais, de dispositivos de subjetivação. O currículo, desse modo, não pode mais ser visto como o "primo pobre" (SILVA, 1995) das análises pedagógicas, uma vez que ele direciona o processo educativo e a produção de subjetividades na escola.

A noção de subjetividade que norteou a pesquisa é diferente daquela que se relaciona com a versão individualizada dos sujeitos. Essa perspectiva fortemente influenciada pelo projeto da Psicologia enquanto ciência sustentou vertentes teóricas que se baseavam em uma concepção de subjetividade correspondente a um sujeito psicológico universalizado, particularizado e finalizado, como se tivesse uma essência. A noção de subjetividade utilizada aqui é baseada no pensamento de Foucault (2006b) e a entende como um efeito de modos de subjetivação, como "a maneira pela qual o sujeito faz a experiência de si mesmo em um jogo de verdade, no qual ele se relaciona consigo mesmo" (FOUCAULT, 2006b, p. 236).

Ao afirmar que "não é o poder, mas o sujeito, que constitui o tema geral de minha pesquisa" (1995, p. 232), Foucault procurou refutar a ideia de um sujeito transcendental, sem história, estável, centrado e individualizado. Para ele, não existe sujeito fora dos processos sociais, fora de um discurso que o produz como tal. Foucault desloca o sujeito antes relacionado a uma posição de origem para uma posição de efeito.

Nesse sentido, a subjetividade pode ser entendida como resultado de modos de subjetivação, ou seja, como parte de um "processo pelo qual se obtém a constituição de um sujeito, mais precisamente de uma subjetividade, que evidentemente não passa de uma das possibilidades dadas de organização de uma consciência de si” (FOUCAULT, 2006a, p. 262).

Rose (2001) traz elementos que ajudam a entender por que uma subjetividade é apenas uma possibilidade, e não a única. Ele aponta que as formas pelas quais os seres humanos atribuem sentido as suas experiências têm um sistema próprio, ou seja, "os dispositivos de produção de sentidos - grades de visualização, vocabulários, normas e sistemas de julgamento, não são produzidos pela experiência; eles produzem a experiência" (ROSE, 2001, p. 36). 
Existem, portanto, práticas que localizam e limitam nossas experiências e sentidos. Estas práticas, segundo Rose, são disseminadas em diferentes locais e através de diferentes formas: escolas, famílias, ruas, locais de trabalho, tribunais. Nesta direção, Rose utiliza o termo tecnologias humanas para se referir a "montagens híbridas de saberes, instrumentos, pessoas, sistemas de julgamento, edifícios e espaços, orientados no nível programático, por certos pressupostos e objetivos sobre os seres humanos" (ROSE, 2001, p.38). Para ele, a escola, assim como a prisão e o hospício, faz parte dessas tecnologias que buscam moldar os sujeitos a partir do controle de suas condutas.

Larrosa (1994) aponta que a obra de Foucault é útil para questionar as concepções inertes de subjetividade antes exclusivas e válidas, sem que isto implique que o sujeito não seja capaz de refletir sobre si, mas sim "porque mostra como a pessoa humana se fabrica no interior de certos aparatos (pedagógicos, terapêuticos,...) de subjetivação" (LARROSA, 1994, p. 37). Isto implica que a subjetividade, facilmente remetida a uma interioridade ou identidade, passa a ser entendida como produto provisório das formas de experiência de si, atravessadas pelas relações de poder e de saber. A divisão pensada outrora entre o corpo e a subjetividade é desfeita uma vez que o corpo longe de ser o outro da subjetividade é o lugar onde ela se inscreve. O corpo, portanto, é um dos objetos mais importantes do controle.

Para Foucault (1996), é o discurso que fornece as condições de possibilidade para a produção de determinados tipos de subjetividade. É nele que podem ser encontrados os mecanismos de subjetivação, junto às táticas das relações de poder que excluem outras possibilidades discursivas seja interditando, rejeitando ou separando o verdadeiro do falso, ou fazendo tudo isso de uma só vez.

O pensamento de Foucault é o território no qual podemos pensar a subjetivação, não mergulhando e se afogando em uma suposta interioridade do sujeito. Com ele, é possível captarmos esse processo pelo discurso, pela história, pelo que, de fato, é possível acessar: a exterioridade. O currículo faz parte desta exterioridade. Mais que isso, ele está localizado em uma posição estratégica. É ele quem dá o contorno de nossas experiências, produz as nossas experiências quando cerca nosso terreno de sentidos. Ele é a condição de possibilidade de sermos o que somos, ou melhor, de estarmos como estamos.

\section{Currículo, gênero e subjetividade}

Na pesquisa, gênero é entendido como um "mecanismo através do qual se produzem e se naturalizam as noções de masculino e feminino" (BUTLER, 2006, p. 70). Para além das diferenças sexuais, compreendemos gênero como um conjunto de normas, como um efeito performático de subjetivação, que adquire estabilidade em função da repetição e reiteração de normas. Essa noção de gênero mostra que é possível pensá-lo não apenas em termos das diferenças sexuais, mas como um conjunto de normas, de discursos e de práticas, como uma tecnologia ${ }^{2}$ social que envolve relações de poder que participa diretamente no processo de subjetivação.

Butler (2006) coloca que é justamente pela confirmação das normas de gênero que os corpos sexuados vão passar a ser pensados como diferentes e naturais. Ou seja, antes de ser apenas aquela categoria que dá sentido social às formas pretensamente naturais dos sexos, gênero é também responsável por reiterar este caráter natural dos sexos.

A autora traz a noção de gênero como norma, que tanto pode naturalizar como subverter as noções estabelecidas de masculino e de feminino. Nesse sentido, ela aponta que gênero pode ser entendido também como mecanismo que pode desconstruir e desnaturalizar padrões. Ela afirma ainda que a generificação é construída, dentre outras coisas, pelas relações que buscam diferenciar os sujeitos. Com isso, "submetido ao gênero, mas subjetivado pelo gênero, o 'eu' não precede nem segue $\mathrm{o}$ processo dessa generificação, mas emerge apenas no interior das próprias relações de gênero e como matriz dessas relações" (BUTLER, 2007, p. 160).

Conforme já pontuamos, o currículo direciona o processo educativo, produz subjetividades e, portanto, enquadra pessoas em determinados modelos. A noção de gênero aqui utilizada ajuda na compreensão e na visualização das tecnologias e normas de gênero presentes no currículo. Alambert (2008) coloca que a escola é uma instituição que "ocupa um lugar preponderante quanto à educação diferenciada, reforçando de modo formal a postura assumida pela família no processo discriminatório; filas de meninos e meninas, brincadeiras e esportes diferenciados, orientação profissional distinta para ambos os sexos" (ALAMBERT, 2008, p. 317). Sendo uma instituição moderna, a escola vem se caracterizando ainda hoje como disciplinadora (ALVES, 2010) e diferenciadora (LOURO, 2007a).

Desde seus inícios, a instituição escolar exerceu uma ação distintiva. Ela se 
incumbiu de separar os sujeitos tornando aqueles que nela entravam distintos dos outros, os que a ela não tinham acesso. Ela dividiu também, internamente, os que lá estavam, através de múltiplos mecanismos de classificação, ordenamento e hierarquização. A escola que nos foi legada pela sociedade ocidental moderna começou por separar adultos de crianças, católicos de protestantes. Ela também se fez diferente para ricos e para os pobres e ela imediatamente separou os meninos das meninas (LOURO, 2007a, p. 57).

Negando esse interesse pelas questões de gênero, de maneira silenciosa, a escola normaliza e disciplina os sujeitos com padrões estabelecidos, regulamentos e legislações que separam, ordenam e normalizam os/as alunos/as.

Segundo Britzman (2007), a escola tradicionalmente tem feito com que se esperem respostas estáveis, uma vez que esse lugar é povoado por modos autoritários de interação social, o que impede o desenvolvimento de uma curiosidade que poderia levar professores/as e estudantes a multiplicar as possibilidades dos modos de viver as relações de gênero e as sexualidades. Para a autora, o lugar do conhecimento mantém as problematizações de gênero e sexualidade no campo da ignorância.

Nesse sentido, a escola busca normalizar as condutas, reduzindo as possibilidades das formas de ser e viver. Podemos fazer essa afirmação porque, conforme observaram Meyer e Soares (2004), "os espaços e os processos pedagógicos estão atravessados de mecanismos e estratégias de vigilância, controle, correção e moldagem dos corpos dos indivíduos - estudantes e docentes - que povoam as instituições escolares" (p. 7 - 8).

É via currículo que ocorre a produção das diferenças e que meninos e meninas são interpelados, por meio de regimes de verdade que ditam modos de vidas diferenciados. Nas filas, nos desenhos, nas danças, nas vestimentas, nas cores, nos gestos, no modo de falar, nos planos em que projetam as futuras profissões, em todos esses elementos e em outros incontáveis, meninos e meninas são diferenciados e colocados em determinadas posições. Nas práticas cotidianas, os processos de subjetivação que incluem as tecnologias e as normas de gênero operam e tentam captar, padronizar, governar e produzir determinados tipos de subjetividades na escola.

Para Louro (2000), mesmo que estas ações estejam mais sutis, mais refinadas, ainda há uma vigilância constante quando se trata de gênero nas escolas e no currículo, uma vez que "expectativas distintas são projetadas para o desempenho intelectual e físico; critérios implícitos de avaliação insinuam-se na apreciação de comportamentos e resultados escolares; aptidões ou tendências são 'identificadas' e sugerem orientações profissionais diferentes" (p. 49-50).

Segundo Novelino (2008), ser homem ou ser mulher constituem traços que compõem a subjetividade, delimitando padrões apropriados de conduta. Assim como Butler, a autora entende a subjetividade não como algo particular ao sujeito relacionada apenas ao aspecto psicológico, mas sim como produto de tecnologias que operam a partir de diversos artefatos culturais. Nesse sentido, ela coloca que "A entrada nos códigos da masculinidade e feminilidade começa nos primeiros momentos de vida com roupas, cores, brinquedos, gestos adequados" (NOVELINO, 2008, p. 311) que depois, como sugere Butler (2007), são reiterados durante toda a vida a partir das relações de poder exercidas pela família, escola, televisão, cinema, especialmente, pela própria pessoa, que, devidamente subjetivada, vai atuar no governo de si.

As subjetividades generificadas são efeitos dessas normas e não condições naturais. Os sujeitos estão cercados de processos de naturalização, de subjetivação que tentam demarcar diferenças de gênero e que ocorrem de maneira privilegiada na escola e no currículo.

A escola e o currículo estão longe de ser meros reflexos das condições sociais. A partir de múltiplas práticas cotidianas banais, a partir de gestos e expressões pouco perceptíveis, pelo silêncio, pelo ocultamento ou pela fala, constroem-se, no espaço propriamente escolar, lugares $e$ destinos sociais. Talvez essa dinâmica nos escape, tal a "naturalização" de que esses processos estão revestidos. Talvez sejam muito sutis os jogos de poder que tecem os currículos, os programas, as normas ou as avaliações escolares (LOURO, 2005, p. 91-92).

A escola exerce uma pedagogia de gênero e coloca em ação as tecnologias de governo, processos que se completam com o autogoverno. Por outro lado, ela abre possibilidades para as resistências. Por isso, o currículo pode ser entendido como "prática subjetivadora" (CORAZZA, 2001, p. 57) que proporciona 
reações múltiplas, incluindo as de resistências aos padrões de gênero.

\section{Aspectos metodológicos da pesquisa}

A partir dos enunciados sobre o filé e a pesca veiculados na comunidade escolar, pelas/os alunas/os, pelos/as professores, pela direção e pelos/as funcionários/as, a pesquisa concentrou-se em como os meninos são interpelados por esses enunciados, ou seja, nas técnicas de subjetivação em termos de gênero que estão operando na escola. As análises se desenvolveram com base nas ferramentas teóricas fornecidas por Foucault, principalmente a noção de discurso como produtor de verdades, de normalidades e anormalidades, enfim, de formas de ser e de viver (FOUCAULT, 1996), representadas no currículo.

O recorte que direcionou a realização da investigação para as turmas dos anos finais do ensino fundamental e também para os processos de subjetivação dos meninos foi sugerido pelas indicações de outra pesquisa (MESQUITA et al, 2011), onde se observou que no bairro os meninos são afastados da confecção do filé logo que vão crescendo, com aproximadamente onze, doze anos, em um momento que coincide com a passagem deles nos anos finais do ensino fundamental.

Foram realizadas observações nos diversos ambientes da escola, entrevistas e grupos de discussão como meios de acesso aos enunciados sobre o filé e a pesca, que permitiram pensar os processos de subjetivação em termos de gênero na escola. Tanto as entrevistas como as discussões dos grupos foram registrados por meio de gravador de voz, após o prévio acordo com os/as participantes/responsáveis ${ }^{3}$. As observações foram registradas em diário de campo, estas quase sempre foram atravessadas por conversas informais, também registradas neste instrumento de pesquisa.

Nas análises da pesquisa foram utilizadas algumas atitudes metodológicas sugeridas por Fischer (2003) com base nas contribuições de Foucault. Partimos, então, dos seguintes aspectos: a linguagem e o discurso são lugares de lutas permanentes; os enunciados são raros e não são, portanto, únicos e óbvios; é preciso atentar às práticas discursivas e não discursivas; é preciso manter uma atitude de distanciamento e de dúvida diante dos aspectos investigados.

Partir da noção de que o discurso é um lugar de luta permanente é considerar, assim como Foucault, que o discurso não pode ser visto apenas como um conteúdo representado por um sistema de signos, mas sim como "práticas que formam sistematicamente os objetos de que fala" (FOUCAULT, 2012, p. 60). Para Foucault, as palavras e as coisas se relacionam de maneira complexa, porque essa relação é histórica, estando repleta de construções e interpretações, sendo perpassada por relações de poder, produzindo sujeitos, subjetividades e compondo modos de subjetivação.

Para analisar esses modos de subjetivação, é preciso, então, descrever a dispersão dos acontecimentos discursivos "através dos quais, graças aos quais e contra os quais" (GREGOLIN, 2007) se estabelecem os regimes de verdade que atravessam e constituem os sujeitos. Considerar que os enunciados são raridades é pensá-los com base em suas condições de existência, é problematizá-los e localizar seus efeitos de verdade, é questionar sua aparição mostrando, por exemplo, como eles surgem em detrimento de outros que são excluídos, rejeitados e tidos como falsos em determinados momentos e lugares.

Nesse sentido, descrever enunciados é entender como as coisas ditas são acontecimentos que ocorrem em contornos muito específicos "no interior de uma certa formação discursiva - esse feixe complexo de relações que 'faz' com que certas coisas possam ser ditas (e serem recebidas como verdadeiras), num certo momento e lugar" (FISCHER, 2003, p. 373).

Atentar para as práticas discursivas e não discursivas é investigar e tornar visíveis os efeitos dessas práticas, que podem tanto ser exercidas a partir daquilo que é "propriamente discursivo (linguagem, discurso, enunciado) como também podem ser observadas em práticas institucionais (exercícios, rituais, definição de lugares e posições, distribuição espacial dos sujeitos, etc.) práticas que jamais "vivem" isoladamente" (FISCHER, 2003, p. 387).

É interessante, nessa perspectiva, observar essas práticas produzidas nas relações de saber/poder de determinada época e descrever os enunciados considerados verdadeiros, que estão presentes no cotidiano, interpelando os sujeitos e produzindo determinadas formas de viver. Desse modo, buscamos "ampliar o leque das práticas a descrever no que se refere a uma temática e a um problema levantado, entendendo que há uma força nas práticas institucionais e que há igualmente uma força considerável nas construções discursivas correspondentes" (FISCHER, 2003, p. 382).

Nesse sentido, a noção de discurso de Foucault mostrou-se bastante interessante para as análises desta pesquisa, uma vez que o a investigação buscou entender como ocorre a 
produção de subjetividades na escola a partir dos enunciados sobre o filé e a pesca.

\section{Produção e naturalização das diferenças na escola}

O pensamento de Foucault vem servindo de ferramenta para diversos estudos que buscam entender como nos tornamos sujeitos, mais precisamente como se constituem nossas subjetividades, como se dão os processos de subjetivação em diferentes contextos.

Determinados modos de agir, de viver, de se vestir, de se divertir, de falar, de se comportar, de se conduzir são amplamente divulgados, por exemplo, por meio do cinema (LAURETIS, 1994; GIROUX, 1996), dos programas televisivos (FISCHER, 2007), da mídia (PARAISO, 2007), dos periódicos científicos, jornais e internet (HÜNING, 2008). Neste trabalho, especificamente, buscamos analisar como nos tornamos sujeitos de gênero. Dito de outra forma, buscamos analisar as tecnologias de subjetivação que atuam na vida dos meninos a partir dos enunciados que circulam na escola em que estudam, sobre uma determinada norma de gênero, que amarra o filé ao feminino e a pesca ao masculino.

Esta norma pode ser entendida como um elemento a partir do qual "certo exercício do poder se acha fundado e legitimado" (FOUCAULT, 2002, p. 62). Nesse sentido, ela atua nos processos de subjetivação na escola estudada, qualificando condutas e, principalmente, corrigindo as consideradas inadequadas.

A frequência diária na escola, a convivência com os professores, com os demais colegas, com a direção, com os que ali trabalham em outras diversas funções, aliada às experiências vividas para além do espaço escolar configura-se como um campo de possibilidades de subjetivação

Dizer que não faz filé, nesse caso, significa mais do que dizer que não tem vontade, que não tem interesse, que não gosta dessa atividade artesanal. Significa dizer que não é mulher para fazer filé.

Foucault observou, ao investigar a história da sexualidade, que existem técnicas que fazem com que os indivíduos efetuem "operações sobre os seus corpos, sobre as suas almas, sobre o seu próprio pensamento, sobre a sua própria conduta, e isso de tal maneira a transformarem-se a eles próprios, a modificarem-se" (FOUCAULT, 1993, p. 201). Essas operações foram por ele nomeadas de tecnologias ou técnicas do eu. Para Foucault, a partir daí, tornou-se interessante levar em conta as composto por manifestações e propagação de supostas verdades.

Rose (2001) coloca que as formas pelas quais atribuímos sentido às nossas experiências têm um funcionamento específico, composto por dispositivos de produção de sentidos, grades de visualização, vocabulários, normas e sistemas de julgamento tidos como verdadeiros e que moldam as nossas vivências através de práticas que ditam as condições de nossas experiências e que operam em diferentes locais: escolas, famílias, ruas, ambiente de trabalho, por exemplo.

Uma dessas verdades, dessas grades de visualização, dessas normas, ou seja, um desses dispositivos de produção de sentidos presente nas vidas dos sujeitos que participaram da pesquisa aqui apresentada é a de que homens pescam e mulheres fazem filé. O propósito da pesquisa foi utilizar estes dois elementos, presentes no cotidiano dos alunos, para pensar as relações de gênero e tentar captar as tecnologias de subjetivação que atuam na escola.

Partimos do pressuposto de que o que falamos não está descolado das nossas experiências, do que ouvimos. As nossas palavras propagam discursos produzidos e envolvidos numa rede de supostas verdades e de relações de poder e que estamos sempre obedecendo a um conjunto de regras dadas historicamente e tidas como verdadeiras (FISCHER, 2001). Ou seja, partimos do pressuposto de que os enunciados das/os alunas/os, dos/ professores/as, dos/as funcionários/as trazem indícios dos discursos que circulam na escola.

Desse modo, quando um aluno diz "Oxe, eu sou macho, professor! Eu sou espada! E eu sou mulher pra fazer filé?", seu enunciado põe em jogo um conjunto de elementos referente às possibilidades de aparecimento, às normas de gênero do lugar em que vive, faz parte de uma formação discursiva relacionada, principalmente, à divisão sexual do trabalho.

técnicas do eu além das de dominação nas análises genealógicas do sujeito nas sociedades ocidentais, ou seja, quando se buscar investigar as formas de constituição das subjetividades.

Digamos que se tem de levar em conta a interação entre estes dois tipos de técnicas, os pontos em que as tecnologias de dominação dos indivíduos uns sobre os outros recorrem a processos pelos quais o indivíduo age sobre si próprio e, em contrapartida, os pontos em que as técnicas do eu são integradas em estruturas de coerção (FOUCAULT, 1993, p. 207). 
Nesse sentido, o modo como os sujeitos são conhecidos relaciona-se ao modo como se conhecem a si próprios. É nessa relação que Foucault vai colocar que o governo não é "uma maneira de forçar as pessoas a fazer o que o governador quer. O governo é sempre um difícil e versátil equilíbrio de complementaridade e conflito entre técnicas que asseguram a coerção e processos por meio dos quais o eu é construído e modificado por si próprio" (FOUCAULT, 1993, p. 207).

Nos enunciados que circulam na escola sobre o filé e a pesca estão presentes algumas tecnologias de subjetivação de gênero que funcionam regulando, organizando, moldando, enfim, demarcando os modos de ser dos sujeitos que lá estudam. O principal propósito dessas tecnologias é naturalizar crenças, fazendo com que elas passem a operar como verdades para os sujeitos e produzindo, então, maneira de ser e viver. Esses discursos, essas tecnologias estão no currículo e visam ao governo das condutas, buscam subjetivar.

São estabelecidos modos considerados corretos de brincar, de estudar, de falar, de se relacionar com o filé e com a pesca, modos de viver que acabam se tornando conhecidos e tidos como naturais pelos sujeitos. Um conjunto de condutas que busca parecer o mais correto, o mais viável, o mais conveniente, em última análise, o único possível para os sujeitos. Os enunciados dos próprios/as alunos/as, dos/as professores/as, dos/as funcionários/as convidam os meninos a viverem de determinadas formas, como "meninos de verdade", "cabra macho mesmo", a não fazer filé.

As análises empreendidas na pesquisa buscaram localizar os acasos dos discursos que camuflam os processos de naturalização e que apresentam verdades como inquestionáveis. Buscaram analisar as relações de poder que fazem com que determinadas formas de ser e viver sejam contempladas nestes discursos ao mesmo tempo em que outras são desqualificadas, colocadas no campo da impossibilidade. O masculino e o feminino são divulgados nos enunciados como características inatas e universais e, portanto, são as bases para a padronização das formas de viver a feminilidade e a masculinidade.

Louro (2005) aponta que "há uma obrigatoriedade de 'preferir' determinados interesses, de desenvolver habilidades ou saberes compatíveis com as referências socialmente admitidas para masculinidade e para feminilidade" (p. 91). Isso resulta no desconforto dos meninos, quando diante de atividades ou práticas tidas como não naturais para o gênero masculino e também quando não possuem habilidades em atividades que tidas como próprias ao masculino.

Desse modo, observamos alguns enunciados através dos quais os meninos buscam mostrar na escola que não fazem filé e, portanto, que não se envolvem com o que é feminino: "de filé, eu não sei nada não", "eu não quis aprender", "não gosto","

Rose (1998) coloca que, mesmo que pareça que "pensamentos, sentimentos e ações constituem o próprio tecido e constituição do mais íntimo eu, eles são socialmente organizados e administrados nos mínimos detalhes" (p. 31). Nesse sentido, esses enunciados, longe de expressarem as mais íntimas vontades dos meninos, atuam na relação do sujeito consigo, como técnicas de si que:

Permitem aos indivíduos efetuarem um
certo número de operações sobre seus
corpos, sobre suas almas, sobre seu
próprio pensamento, sobre sua própria
conduta, e isso de tal maneira a
transformarem-se a eles próprios, a
modificarem-se, ou a agirem num certo
estado de perfeição, de felicidade, de
pureza, de poder sobrenatural e assim por
diante (FOUCAULT, 1993, p. 207).

Nesses enunciados, os meninos avaliamse e posicionam-se como aqueles que não fazem filé. Eles produzem um saber sobre si mesmo, amparados na normatividade da demarcação de gênero entre o filé e a pesca. Nesse mesmo movimento eles produzem também um saber sobre outros, que são posicionados de diferentes formas caso estejam ou não envolvidos com o filé, eles pensam e avaliam uns aos outros, conforme o enunciado a seguir "Eu acho bom, mas não sei, os meus colegas, eles acham meio esquisito homem que faz filé,",

São essas estratégias de governo de si e dos outros que dão sentido ao caráter performático de gênero, ao produzir subjetividades generificadas, uma vez que a performatividade "é sempre uma reiteração de uma norma ou conjunto de normas" (BUTLER, 2007, p. 167). As normas de gênero "expressam-se por meio de recomendações repetidas e observadas cotidianamente, que servem de referência a todos" (LOURO, 2008, p. 22). Quem aceita as sugestões é considerado "normal", quem se posiciona fora delas é tido como "anormal".

Por meio dos enunciados e dos seus efeitos de verdade, de maneira exaustiva e contínua, os meninos produzem verdade sobre 
eles mesmos. Para isso, utilizam as técnicas de si que não são inventadas por eles. De acordo com Corazza (2001), essas técnicas são "esquemas que eles encontram em sua cultura e que lhes são propostos, sugeridos, impostos pela sociedade e grupos sociais" (p. 61).

$\mathrm{Na}$ escola investigada, os meninos são discriminados, caso haja indícios de que participam de alguma forma do processo de confecção do filé, sendo chamados publicamente de "mulherzinhas" e "gayzinhos" quando são vistos fazendo ou vendendo filé. Sales (2010) observa que as técnicas de zuação, ou seja, aquelas que funcionam apontando publicamente os sujeitos de forma a ironizar ou ridicularizar seus comportamentos tidos como desviantes das normas atuam com fins de governo e de maneira bastante eficiente. A pesquisadora mostra que, em sua investigação, além dos alunos, os profissionais também acionam estas técnicas na escola com objetivos considerados pedagógicos.

$\mathrm{Na}$ pesquisa realizada por Sales, a professora observada usa essa técnica quando diz publicamente na sala de aula que irá obrigar alguns alunos a usarem rosa em uma atividade com o objetivo de fazer com que eles parassem de atrapalhar a aula, ou seja, como castigo.

De maneira semelhante, na escola aqui analisada, o funcionário responsável por observar os/as alunos/as no pátio também utiliza esta técnica para chamar a atenção dos meninos. Com a pergunta "E aí, já fez um filezinho hoje?" feita estrategicamente quando os meninos estão muito agitados, ele objetiva colocar estes sujeitos em uma situação constrangedora e assim deixá-los mais calmos e pensativos. A técnica da zuaçao, apontada por Sales (2010) e observada também nesta pesquisa visa governar o comportamento dos meninos, moldando uma conduta considerada adequada a um verdadeiro menino e fazendo também com que eles fiquem quietos.

Há, nos enunciados que circulam na escola, um interessante processo de naturalização, uma recorrente tentativa de mostrar que é natural a mulher gostar de fazer filé, ter mais jeito, mais habilidades motoras finas, mais paciência, senso estético e que os homens são naturalmente bons pescadores porque são mais fortes fisicamente, mais corajosos: "Filé é mais pra feminino e pesca é mais pra masculino",; "Oxe, se brincar menina já nasce sabendo fazer filé10" "Filé é mais para mulher mesmo, pesca é pro homem, todo mundo diz isso aqui, o pessoal do bairro, as mulheres também" "11.

Desse modo, notamos que "Nossas personalidades, subjetividades e 'relacionamentos' não são questões privadas, se isso significa dizer que elas não são objeto de poder. Ao contrário, elas são intensivamente governadas" (ROSE, 1998, p. 30).

\section{Considerações finais}

O fato de grande parte dos meninos não demonstrarem interesse pelo filé, conforme observamos nesta pesquisa, é resultado do investimento de um processo de governo das relações de gênero que objetiva determinar as possibilidades de ser e viver como um menino, estabelecendo fronteiras claras entre o que é feminino e o que é masculino. As técnicas de si e as técnicas de dominação parecem atuar conjuntamente na escola analisada, buscando desqualificar aqueles meninos que fazem filé. Estas técnicas produzem efeitos, fazem um nó cego entre ser homem e pescar e ser mulher e fazer filé, levando os sujeitos a desacreditarem na possibilidade de ser menino e ser rendeiro.

Essas técnicas fazem muitos meninos desistirem de qualquer aproximação com o filé mesmo que essa seja uma possibilidade de se ganhar dinheiro, mesmo que eles gostem de fazer e achem bonito o artesanato. Estas técnicas governam, demarcam a conduta dos meninos que passam a se autogovernar e a governar os outros.

As demarcações de gênero estão fortemente enraizadas na comunidade onde a escola está situada e definem como norma a divisão social e sexual do trabalho em torno do filé e da pesca. As técnicas de governo na escola propagam discursos sobre os modos de ser com base em uma política de verdade, que divulga o conhecimento sobre certas noções particulares de gênero, em especial, de que fazer filé é coisa de mulher.

\section{Referências}

ALAMBERT, Zuleika. Educação diferenciada: uma realidade. In: COSTA, Ana A. A.; SARDENBERG, Cecília M. B. (Orgs.) Feminismo no Brasil: reflexões teóricas e perspectivas. Salvador: UFBA / Núcleo de Estudos Interdisciplinares sobre a Mulher, 2008, p.315-322.

ALVES, Juliana Carla da Paz. Currículo, cultura escolar e disciplinamento. 2010. $93 \mathrm{f}$. Dissertação (Mestrado em Educação) Universidade Federal de Alagoas, Maceió, 2010. 
BRITZMAN, Deborah P. Curiosidade, sexualidade e currículo. In: LOURO, Guacira L. $O$ corpo educado. Pedagogias da sexualidade. Belo Horizonte: Autêntica, 2007, p. 83-112

BUTLER, Judith. Deshacer el gênero. Buenos Aires: Paidos, 2006.

Corpos que pesam: sobre os limites discursivos do sexo. In: LOURO, Guacira. L. (Org.). O corpo educado: pedagogias da sexualidade. Belo Horizonte: Autêntica, 2007, p. 151-172.

CORAZZA, Sandra. O que quer um currículo? - pesquisas pós-criticas em educação. Petrópolis: Vozes, 2001.

FISCHER, Rosa M. B. Foucault e a análise do discurso em educação. Cadernos de Pesquisa. Rio de Janeiro, n. 114, p. 197-223, 2001.

Foucault revoluciona a pesquisa em educação? Perspectiva. Florianópolis, v. 21, n. 2, 2003, p. 371-389.

Verdades em suspenso: Foucault e os perigos a enfrentar. In: COSTA, Marisa V. (Org.) Caminhos investigativos II: outros modos de pensar e fazer pesquisa em educação. Rio de Janeiro: Lamparina editora, 2007, p. 48-70.

FOUCAULT, Michel. Verdade e subjectividade (Howison Lectures). Revista de Comunicação e linguagem. $\mathrm{n}^{\circ}$ 19. Lisboa: Edições Cosmos, 1993. p. 203-223.

O sujeito e o poder. In: DREYFUS, Hubert. L.; RABINOW, Paul. Michel Foucault uma trajetória filosófica: para além do estruturalismo e da hermenêutica. Rio de Janeiro: Forense-Universitária, 1995. p. 231-249.

A ordem do discurso: aula inaugural no Collège de France, pronunciada em 2 de dezembro de 1970. Campinas: Loyola, 1996.

Subjetividade e verdade. In:

Resumo dos cursos do Collège de France (19701982). Rio de Janeiro: Jorge Zahar Editor, 1997. p. 107-115.

2002.

Os anormais. São Paulo: Martins Fontes,
O Retorno da Moral. In: MOTTA, Manoel. B. (Org). Ditos e escritos V. Rio de Janeiro: Forense Universitária, 2006a.

Foucault. In: MOTTA, Manoel. B. (Org). Ditos e escritos V. Rio de Janeiro: Forense Universitária, 2006b.

A arqueologia do saber. Rio de Janeiro: Forense Universitária, 2012.

GIROUX, Henry A. O filme Kids e a política de demonização da juventude. Educação e Realidade, Porto Alegre, v. 21, n. 1,. p.123-36, jan./jun. 1996.

GREGOLIN, Maria do R. Foucault e Pêcheux na análise do discurso: diálogos e duelos. São Carlos: Claraluz, 2007.

HÜNING, Simone M. O sujeito biotecnológico na viagem pelo reino das batatas transgênicas, porquinhos fosforescentes e almas codificadas. 143 f. Tese (Doutorado em Psicologia). Pontifícia Universidade Católica do Rio Grande do Sul, Porto Alegre, 2008.

LARROSA, Jorge. Tecnologias do eu e educação. In: SILVA, Tomaz T. (Org.). O sujeito da educação: estudos foucaultianos. Petrópolis: Vozes, 1994, p. 35-86.

LAURETIS, Tereza. A tecnologia do gênero. In: HOLLANDA, Heloísa B. de. (Org.). Tendências e impasses: o feminismo como crítica da cultura. Rio de Janeiro: Rocco, 1994, p. 206-242.

LOURO, Guacira L. Currículo, Género e Sexualidade. Porto: Porto Editora, 2000.

O currículo e as diferenças sexuais e de gênero. In: COSTA, Marisa V. (Org.). O currículo nos limiares do contemporâneo. Rio de Janeiro: DP\&A, 2005, p. 85-92.

Gênero, sexualidade e educação: uma perspectiva pós-estruturalista. Petrópolis: Vozes, 2007a.

Pedagogias da sexualidade. In:

$\overline{\text { (Org.). }}$ O corpo educado: pedagogias $\overline{\text { da }}$ sexualidade. Belo Horizonte: Autêntica, 2007b, p. 9-34.

Gênero e sexualidade: pedagogias contemporâneas. Pró-Posições. Campinas, v. 19, n. 02, p. 17-23, 2008. 
MESQUITA, Marcos R.; ALVES, Julia M. D.; MARTINS, Mário H. da M. Gênero, arte e cultura: discutindo o caso dos rendeiros do Pontal da Barra. In: LEITÃO, Heliane de A. L. (Org.) Coisas do gênero: diversidade e desigualdade. Maceió: EDUFAL, 2011.

NOVELINO, Aída M. Masculino/Feminino: Uma análise micro-política In: COSTA, Ana A. A.; SARDENBERG, Cecília M. B. (Orgs.) Feminismo no Brasil: reflexões teóricas e perspectivas. Salvador: UFBA / Núcleo de Estudos Interdisciplinares sobre a Mulher, 2008, p.309-314.

PARAÍSO, Marlucy A. Currículo e mídia educativa brasileira: poder, saber e subjetivação. Chapecó: Argos, 2007.

POPKEWITZ, Thomas S. História do currículo, regulação social e poder. In: SILVA, Tomaz T. (Org.). O sujeito da educação: estudos foucaultianos. Petrópolis: Vozes, 1994, p. 173210 .

ROSE, Nikolas. Governando a alma: a formação do eu privado. In: SILVA, Tomaz T. (Org).
Liberdades reguladas: a pedagogia construtivista e outras formas de governo do eu. Petrópolis: Vozes, 1998, p. 30-45.

. Como se deve fazer a história do eu? Educação \& Realidade. Porto Alegre, v. 26, n. 1, p. $34-57,2001$.

SILVA, Tomaz T. Os novos mapas culturais e o lugar do currículo numa paisagem pós-moderna. In: SILVA, Tomaz T. da; MOREIRA, Antonio F. Territórios contestados: $O$ currículo e os novos mapas políticos e culturais. (Orgs). Petrópolis: Vozes, 1995, p. 184-202.

. Documentos de Identidade: Uma introdução às teorias do currículo. Belo Horizonte: Autêntica, 2005.

O currículo como fetiche: a poética e a política do texto curricular. Belo Horizonte: Autêntica, 2006.

SOLER, Rodrigo D. de V. Y. Uma história política da subjetividade em Michel Foucault. Fractal, Rev. Psicol., Rio de Janeiro, v. 20, n. 2, 2008. 


\section{Notas}

$1 \mathrm{O}$ filé é uma renda artesanal de origem desconhecida cujo processo de confecção não deixa dúvida de que surgiu a partir da rede de pesca, a tarrafa, tendo também múltiplas influências européias. A confecção do filé passa, inicialmente, pela preparação de uma rede, também chamada de malha que é esticada em um tear, Posteriormente, esta rede é preenchida com diversos pontos e formas, na maioria das vezes, bastante coloridas dando forma as peças (marcadores de páginas, toalhas de mesa, blusas, vestidos, saias, dentre outras), que ficam prontas para serem utilizadas ou comercializadas.

2 O termo tecnologia é aqui utilizado como a articulação de certas técnicas e de certos tipos de discursos acerca de gênero, de maneira semelhante à sugerida por Foucault (1993), quando ele trata da genealogia do sujeito.

3 O projeto desta pesquisa foi aprovado pelo Comitê de ética em Pesquisa do Centro Universitário Cesmac, com o $\mathrm{n}^{\mathrm{o}}$ de protocolo 1274/2012.

4 Trecho da fala de um aluno do $6^{\circ}$ ano durante uma observação no pátio da escola ao responder a pergunta:

"E aí, já fez um filezinho hoje?" feita por um funcionário, chamado de professor pelo aluno.

5 Trecho da fala de um aluno do $8^{\circ}$ ano durante o grupo de discussão.

6 Trecho da fala de um aluno do $9^{\circ}$ ano durante entrevista.

7 Trecho da fala de um aluno do $7^{\circ}$ ano durante entrevista

8 Trecho da fala de um aluno do $7^{\circ}$ ano, durante entrevista.

9 Trecho da fala de um aluno do $9^{\circ}$ ano durante entrevista.

10 Trecho da fala de uma aluna do $8^{\circ}$ ano durante entrevista.

11 Trecho da fala de um aluno do $8^{\circ}$ ano durante entrevista.

Sobre as autoras:

Julia Mayra Duarte Alves: Universidade Federal de Alagoas (Maceió).

Laura Cristina Vieira Pizzi: Universidade Federal de Alagoas (Maceió). 